\title{
Perfil epidemiológico da dengue em um estado do nordeste brasileiro, 2011 a 2015
}

\author{
Perfil epidemiológico del dengue en un estado del noreste de Brasil, 2011 a 2015 \\ Epidemiological profile of dengue in a state on the northeastern brazil, 2011 to 2015
}

Leila Karoline Ferreira dos Santos ${ }^{1}$, Valleska Maria Leão Pessôa ${ }^{1}$, Tâmyssa Simões dos Santos ${ }^{2}$, Gabriela Rodrigues Bragagnollo ${ }^{*}$, Gabriel Pinheiro Machado ${ }^{3}$, Susana I. Segura Munõz ${ }^{3}$, Stephanie Rodrigues Bragagnollo ${ }^{4}$, Marcela das Neves Guimarães ${ }^{2}$, Lucyo Wagner Torres de Carvalho'.

\section{RESUMO}

Objetivo: Analisar o perfil epidemiológico da dengue em um estado do nordeste brasileiro no período de 2011 a 2015. Método: Trata-se de um estudo epidemiológico descritivo de abordagem quantitativa. Resultados: No período de 2011 a 2015, foram notificados 111.773 casos de Dengue no estado de Alagoas, o que resulta em 686,4 casos por 100.000 habitantes. Neste período, os maiores coeficientes de detecções deram-se nos anos de 2012 e 2015, em todas as mesorregiões de Alagoas, com aumento do coeficiente de detecção média do período. Evidenciou-se maior ocorrência dos casos no sexo feminino, de cor parda, em moradores da zona urbana, de faixa etária adulta e com escolaridade até o ensino fundamental. Conclusão: A dengue continua como importante agravo, tendo em vista sua alta incidência, com períodos epidêmicos, e possibilidade de evolução para o óbito. Possuindo assim, grande repercussão para saúde pública do Estado e do país.

Palavras-chave: Dengue, Perfil, Epidemiologia, Incidência.

\begin{abstract}
Objective: Analyze the epidemiological profile of dengue fever in a state of the brazilian northeast in the period from 2011 to 2015. Method: This is an observational and analytical study with a quantitative approach. Results: In the period from 2011 to $2015,111,773$ cases of Dengue in the state of Alagoas were reported, resulting in 686.4 cases per 100,000 inhabitants. In this period, the highest detection coefficients occurred in the years of 2012 and 2015 in all mesoregions of Alagoas, with an increase in the average detection coefficient of the period. It was evidenced a greater occurrence of the cases in the female sex, brown, residents of the urban zone, adult age group and with schooling until elementary school. Conclusion: Dengue continues as an important aggravation in view of the high incidence, with epidemic periods, with evolution to death, and thus with great repercussions on the public health of the State and the country.
\end{abstract}

Keywords: Dengue, Profile, Epidemiology, Incidence.

\footnotetext{
${ }_{1}^{1}$ Universidade Estadual de Ciências da Saúde de Alagoas, Curso de enfermagem, Maceió, AL, Brasil.

${ }^{2}$ Centro Universitário Maurício de Nassau - UNINSSAU, Curso de enfermagem, Maceió, AL, Brasil.

${ }^{3}$ Universidade de São Paulo - USP, Departamento de Saúde Pública da Escola de Enfermagem de Ribeirão Preto. Ribeirão Preto, SP, Brasil. *E-mail: gabriela.rodrigues.bragagnollo@usp.br

${ }^{4}$ Pontifícia Universidade Católica de São Paulo, Campinas, SP, Brasil.
}

Agência de fomento: A Fundação de Amparo à Pesquisa do Estado de Alagoas e Conselho Nacional de Desenvolvimento Científico e Tecnológico pela conseção das bolsas de iniciação científica. 


\section{RESUMEN}

Objetivo: Analizar el perfil epidemiológico del dengue en un estado del nordeste brasileño en el período de 2011 a 2015. Método: Se trata de un estudio epidemiológico descriptivo de abordaje cuantitativo. Resultados: En el período de 2011 a 2015, se notificaron 111.773 casos de Dengue en el estado de Alagoas, lo que resulta en 686,4 casos por 100.000 habitantes. En este período, los mayores coeficientes de detecciones se dieron en los años 2012 y 2015, en todas las mesorregiones de Alagoas, con aumento del coeficiente de detección promedio del período. Se evidenció mayor ocurrencia de los casos en el sexo femenino, de color parda, en moradores de la zona urbana, de grupo de edad adulta y con escolaridad hasta la enseñanza fundamental. Conclusión: El dengue sigue siendo importante agravio, teniendo en vista su alta incidencia, con períodos epidémicos, y posibilidad de evolución para el óbito. Por lo tanto, gran repercusión para la salud pública del Estado y del país

Palavras-chave: Dengue, Perfil, Epidemiologia, Incidência.

\section{INTRODUÇÃO}

A dengue é uma infecção viral sistêmica, classificada como a mais importante arbovirose que ocorre em seres humanos. Devido ao elevado número de casos e ocorrência de óbitos, a doença se tornou, nos últimos anos, um relevante problema de saúde pública, em nível mundial. Seu principal vetor é o Aedes aegypti, um mosquito que possui uma boa adaptação ao clima tropical, em virtude das condições ambientais favoráveis para sua proliferação, e está doença apresenta hiperendemicidade e cocirculação de quatro sorotipos (Den 1, 2, 3 e 4) (DIAS LBA, et al., 2010; SOUZA RP, et al., 2011).

Apresenta amplo espectro quanto às manifestações clínicas, variando da forma assintomática até uma doença grave. A primeira manifestação clínica é a febre súbita ( $39^{\circ} \mathrm{C}$ a $40^{\circ} \mathrm{C}$ ), acompanhada de cefaleia, mialgia, dor retro orbitária, artralgia e presença de exantema, sendo esse representado por $50 \%$ dos casos; nos casos mais graves estes sinais e sintomas podem ser procedidos à dor abdominal intensa e contínua, vômitos persistentes, hipotensão postural, hepatomegalias, hemorragias, sonolência, irritabilidade, hipotermia, aumento do hematócrito, queda de plaquetas, desconforto respiratório, cianose e pulso rápido e fino, que são considerados sinais de alarme (BARRETO ML, et al., 2011).

De acordo com a Organização Mundial de Saúde, estima-se que anualmente ocorre cerca de 50 a 100 milhões de casos de dengue em todo o mundo e, que aproximadamente 2,5 bilhões de pessoas vivem em mais de 100 países endêmicos (SINAN, 2018). Nas Américas os casos de dengue têm se intensificado desde os anos 80, alcançando em 2015 mais de dois milhões de casos, com uma taxa de mortalidade que vem triplicando-se a cada década (ROMERO-VEGAI L, et al., 2014). Os países com as maiores taxas de letalidade foram: Brasil, Colômbia, Equador, Guatemala, Panamá, Peru e República Dominicana (DONALISIO MR, et al., 2017). É relevante destacar que os quatro sorotipos são disseminados por todo o continente, e em oito países, Brasil, Colômbia, Equador, Guatemala, México, Nicarágua, Peru e Venezuela, há circulação simultânea de todos eles (CABEZAS C, et al., 2015).

No ano de 2015, o Brasil contribuiu com o maior número de casos nas Américas, registrando 1.649.008 casos de dengue no país. A Região Sudeste notificou 1.026.226 casos, o maior número no país, seguida pela Região Nordeste com 311.519 casos, dos quais 37.050 dos casos de registros de pessoas infectadas pelo mosquito, ocorreram no Estado de Alagoas, que ocupava a terceira posição no Brasil $(707,6$ casos/100.000 habitantes) (BRASIL, 2012).

Em 2016, foi registrado no Brasil cerca de 1.438 .624 casos de dengue confirmados, sendo 762 de dengue grave e 7.449 de dengue com sinais de alarme, havendo uma pequena redução em comparação ao ano anterior (SILVA MMO, et al., 2016). Em contrapartida, no Estado de Alagoas, as ações de combate ao mosquito Aedes aegypti reduziram os casos, registrando cerca de 21.940 pessoas infectadas, configurando uma diminuição de 40,8\% em relação ao ano de 2015 (ARAÚJO VEM, et al., 2017). 
Atualmente, até a Semana Epidemiológica 15 de 2017, o Nordeste continuava como a $2^{\text {a }}$ região em número de casos (31.142), representando $27,5 \%$ no território nacional. Alagoas sofreu uma redução no número de casos e no atual momento ocupa a $7^{a}$ posição com 582 casos (BRASIL, 2017). Apesar dos avanços do Sistema Único de Saúde no campo da vigilância, promoção da saúde e prevenção das doenças infecciosas, a introdução do vírus da dengue ainda se configura como motivo de preocupação na saúde coletiva (WHO, 2009).

Por conta do turismo, o Estado de Alagoas recebe anualmente pessoas de diversas partes do Brasil. Dessa forma, há um aumento do fluxo de pessoas e assim se eleva o risco de disseminação do vírus. Percebe-se que apesar da redução dos casos, o coeficiente de incidência (17,3/100 mil hab) ainda é significativo. Deve-se considerar também, que o Estado vizinho, Pernambuco, ocupa a 3a posição no Nordeste, em número de casos (BRASIL, 2017).

Neste cenário, julga-se importante destacar também, a subnotificação dos casos. Estudo trata que as notificações de dengue identificadas na maior parte das regiões brasileiras descrevem apenas cerca de $15 \%$ do total notificado. Todavia, se considerarmos que grande parte das infecções pelo vírus da dengue é assintomática (SILVA MMO, et al., 2016), o número real de casos pode ter sido além dos números de casos notificados.

Diante dessa premissa, este estudo permite apontar os principais elementos que definem o perfil epidemiológico da dengue no Estado de Alagoas, levantando dados acerca de componentes importantes que devem ser observados nas ações da vigilância epidemiológica e sanitária, visando o controle da doença. Desse modo, o presente estudo tem como objetivo analisar o perfil epidemiológico da dengue em um Estado do Nordeste brasileiro no período de 2011 a 2015.

\section{MÉTODOS}

\section{Desenho e local do estudo}

Trata-se de um estudo epidemiológico descritivo com abordagem quantitativa. O estudo foi desenvolvido no Estado de Alagoas, o qual situa-se na região Nordeste do Brasil. É dividido geograficamente em três mesorregiões, sendo elas Agreste, Leste e Sertão Alagoano, compreendendo 102 municípios e uma população de 3.358.963 habitantes, registrados no ano de 2016. A área da unidade territorial corresponde a $27.848,14 \mathrm{~km}^{2}$, representando $0,33 \%$ do território nacional, limitando-se a norte e oeste com o Estado de Pernambuco, ao sul com os estados de Sergipe e Bahia e a leste com o oceano Atlântico. Quanto às condições climáticas, tem como principais características as irregularidades da precipitação pluviométrica e a pouca variação sazonal da radiação solar (BARROS AHC, et al., 2012).

\section{Coleta de dados e período}

A coleta de dados foi realizada no mês de abril de 2016, no programa TabNet, através do Sistema de Agravos de Notificação (SINAN), bem como, por meio do banco de dados estadual disponibilizado pela Secretaria Estadual de Saúde de Alagoas, disponibilizados pelo Departamento de Informática do Sistema Único de Saúde - DATASUS, referentes ao número absoluto de casos de dengue notificados em Alagoas.

As variáveis dependentes foram categorizadas em: Mesorregião do Agreste Alagoano, Mesorregião do Leste Alagoano e Mesorregião do Sertão Alagoano; e as independentes, categorizadas como: sociodemográficas (sexo, raça, faixa etária, escolaridade e zona de residência) e específicas (exame sorológico, classificação da Dengue, critérios de confirmação e evolução da doença).

\section{Análise dos resultados e estatística}

Os casos notificados por município e por período foram inseridos no banco de dados, utilizando Microsoft Office Excel, e para o cálculo da taxa de incidência de casos novos (TI), utilizaram-se os dados do SINAN (números de casos notificados-NCN) e do IBGE (ALAGOAS, 2015) (população por ano - NP), esses foram submetidos à fórmula: $T I=(N C N / N P) X 100.000$. 
Para verificar a existência de associação ou relação entre as variáveis dependentes (regiões) e a variáveis independentes (ano, sexo, faixa etária, raça, escolaridade, tipos de dengue, entre outras), foi utilizado teste do Qui-quadrado (teste para variáveis qualitativas grupos independentes), com nível de significância de 5\% $(\alpha$ 0,05). O pacote estatístico utilizado para confecção de gráficos e análise dos dados foi o Bioestat 5.0.

\section{Aspectos éticos}

Este estudo não foi apreciado pelo Comitê de Ética em Pesquisa, uma vez que foi desenvolvido por meio de dados secundários de domínio público (SINAN/SES/AL), não havendo necessidade de contato com os sujeitos da pesquisa.

\section{RESULTADOS}

Considerando as variáveis estudadas, no período de 2011 a 2015, constatou-se 111.773 casos de Dengue no Estado de Alagoas. Ao avaliar os aspectos sociodemográficos, os itens que mais chamaram atenção corresponderam a $56,6 \%$ do sexo feminino, $58,6 \%$ de raça parda, $61,6 \%$ com faixa etária entre 19 a 59 anos, $23 \%$ com ensino fundamental e $66,2 \%$ residiam em área urbana. A partir da análise dos dados citados, podemos inferir que há evidência de associação entre a distribuição dos casos de dengue entre as variáveis sociodemográficas e as mesorregiões, com significância no $p$-valor $<0,0001$. (Tabela 1).

Tabela 1 - Distribuição de casos de dengue segundo aspectos sociodemográficos. Alagoas, 2011 a 2015.

\begin{tabular}{|c|c|c|c|c|c|c|c|c|}
\hline \multirow{3}{*}{ Variável } & \multicolumn{7}{|c|}{ Mesorregião Alagoana } & \multirow{3}{*}{ p-valor } \\
\hline & \multicolumn{2}{|c|}{ Agreste } & \multicolumn{2}{|c|}{ Leste } & \multicolumn{2}{|c|}{ Sertão } & \multirow{2}{*}{$\begin{array}{c}\text { Média } \\
\%\end{array}$} & \\
\hline & $\mathbf{N}$ & $\%$ & $\mathbf{N}$ & $\%$ & $\mathbf{N}$ & $\%$ & & \\
\hline \multicolumn{9}{|l|}{ Sexo } \\
\hline Masculino & 16130 & 45,9 & 25835 & 43,0 & 5509 & 38,5 & 43,3 & \\
\hline Feminino & 19002 & 54,1 & 34150 & 56,8 & 8799 & 61,5 & 56,6 & $<0.0001$ \\
\hline Ignorado/Branco & 10 & 0,0 & 89 & 0,1 & 3 & 0,0 & 0,1 & \\
\hline \multicolumn{9}{|l|}{ Raça } \\
\hline Branca & 4496 & 12,8 & 5275 & 8,8 & 1402 & 9,8 & 10,2 & \\
\hline $\begin{array}{l}\text { Preta } \\
\text { Amarela }\end{array}$ & $\begin{array}{c}1329 \\
137\end{array}$ & $\begin{array}{l}3,8 \\
0,4\end{array}$ & $\begin{array}{c}3785 \\
263\end{array}$ & $\begin{array}{l}6,3 \\
0,4\end{array}$ & $\begin{array}{c}672 \\
68\end{array}$ & $\begin{array}{l}4,7 \\
0,5\end{array}$ & $\begin{array}{l}5,3 \\
0,4\end{array}$ & $<0.0001$ \\
\hline Parda & 26062 & 74,2 & 28830 & 48,0 & 9244 & 64,6 & 58,6 & \\
\hline Indígena & 121 & 0,3 & 294 & 0,5 & 114 & 0,8 & 0,5 & \\
\hline Ignorado/Branca & 2997 & 8,5 & 21627 & 36,0 & 2811 & 19,6 & 25,0 & \\
\hline \multicolumn{9}{|l|}{ Faixa etária } \\
\hline Criança (0 a 11) & 5043 & 14,4 & 9269 & 15,4 & 3064 & 21,4 & 15,9 & \\
\hline Adolescente (12 a 18) & 5875 & 16,7 & 9619 & 16,0 & 2169 & 15,2 & 16,1 & \\
\hline Adulto (19 a 59) & 21564 & 61,4 & 37997 & 63,3 & 7869 & 55,0 & 61,6 & $<0.0001$ \\
\hline Idoso (60 ou mais) & 2659 & 7,6 & 3189 & 5,3 & 1208 & 8,4 & 6,4 & \\
\hline Ignorado/Branco & 1 & 0,0 & 0 & 0,0 & 1 & 0,0 & 0,0 & \\
\hline \multicolumn{9}{|l|}{ Escolaridade } \\
\hline Analfabeto & 634 & 1,8 & 1015 & 1,7 & 480 & 3,4 & 1,9 & \\
\hline Ensino Fundamental & 5624 & 16,0 & 14954 & 24,9 & 4795 & 33,5 & 23,2 & \\
\hline Ensino Médio & 1417 & 4,0 & 4954 & 8,2 & 1269 & 8,9 & 7,0 & $<0.0001$ \\
\hline Ensino Superior & 261 & 0,7 & 801 & 1,3 & 320 & 2,2 & 1,3 & \\
\hline $\begin{array}{l}\text { Não se aplica } \\
\text { Ignorado/Branco }\end{array}$ & $\begin{array}{l}3000 \\
2420\end{array}$ & $\begin{array}{r}8,5 \\
68,9\end{array}$ & $\begin{array}{c}5385 \\
32965\end{array}$ & $\begin{array}{r}9,0 \\
54,9\end{array}$ & $\begin{array}{l}2012 \\
5435\end{array}$ & $\begin{array}{l}14,1 \\
\mathbf{3 8 , 0}\end{array}$ & $\begin{array}{c}9,5 \\
57,2\end{array}$ & \\
\hline \multicolumn{9}{|l|}{ Zona de residência } \\
\hline Urbana & 26720 & 76,0 & 42895 & 71,4 & 2863 & 20,0 & 66,2 & \\
\hline Rural & 2519 & 7,2 & 712 & 1,2 & 378 & 2,6 & 3,3 & $<0.0001$ \\
\hline Ignorado/Branco & 5903 & 16,8 & 16467 & 27,4 & 1107 & $\mathbf{7 7 , 4}$ & 30,5 & \\
\hline
\end{tabular}


Quanto ao coeficiente de detecção, os dados revelam que os mais elevados foram nos anos de 2012 e 2015, em todas as mesorregiões, sendo esses respectivamente, 1053,2/100.000 casos (53\%) e $1030,5 / 100.000$ casos (50\%) no Estado de Alagoas, alcançando um coeficiente acima da detecção média do período estudado, de aproximadamente $686,9 / 100.000$ casos. O menor coeficiente de detecção ocorreu no ano de 2011, apresentando 381,5 casos/100.000 habitantes. A mesorregião leste alagoana apresentou os maiores índices de detecção no período observado, com exceção do ano de 2015 que foi superada pela mesorregião agreste (Tabela 2).

Tabela 2 - Coeficientes de deteç̧ão por 100.000 habitantes, de casos confirmados de dengue no Estado de Alagoas e suas mesorregiões. Alagoas, 2011 a 2015.

\begin{tabular}{lccccc}
\hline \multirow{2}{*}{ Mesorregião } & \multicolumn{5}{c}{ Anos } \\
\cline { 2 - 6 } & $\mathbf{2 0 1 1}$ & $\mathbf{2 0 1 2}$ & $\mathbf{2 0 1 3}$ & $\mathbf{2 0 1 4}$ & $\mathbf{2 0 1 5}$ \\
\hline Agreste Alagoano & 595,1 & 1094,8 & 989,0 & 679,8 & 2045,6 \\
Leste Alagoano & 1243,1 & 3849,1 & 1233,6 & 1610,4 & 1746,9 \\
Sertão Alagoano & 75,6 & 346,9 & 191,6 & 163,1 & 1407,6 \\
Alagoas & $\mathbf{3 8 1 , 5}$ & $\mathbf{1 0 5 3 , 2}$ & $\mathbf{4 7 9 , 9}$ & $\mathbf{4 8 6 , 9}$ & $\mathbf{1 0 3 0 , 5}$ \\
\hline
\end{tabular}

Fonte: SINAN/SES/AL, 2016.

Na Tabela 3, são apresentados os casos quanto ao exame sorológico, classificação dos casos notificados de dengue e evolução da doença. Houve evidências de associação entre a distribuição dos casos quanto a esses parâmetros e as mesorregiões, com significância no $p$-valor $<0,0001$. A maior taxa média de confirmação da doença foi por critério clínico-epidemiológico, em 70,93\% dos casos, seguido de 10,70\% confirmados por diagnóstico laboratorial. No tocante à classificação dos casos de dengue, 67,27\% foram classificados como dengue clássica e $0,61 \%$ dos casos como dengue grave. Cabe ressaltar, que a soma dos percentuais de inconclusivo mais ignorado/branco totalizaram em $32,13 \%$ dos casos, desta forma, não foram classificados. Ainda é relevante apontar que, quanto à evolução da doença, $21,55 \%$ dos casos foram ignorados/branco. (Tabela 3).

Tabela 3- Dados de confirmação, classificação e evolução da dengue nas mesorregiões. Alagoas, 2011-2015.

\begin{tabular}{|c|c|c|c|c|c|c|c|c|}
\hline \multirow{3}{*}{ Variável } & \multicolumn{7}{|c|}{ Mesorregião Alagoana } & \multirow{3}{*}{ p-valo } \\
\hline & \multicolumn{2}{|c|}{ Agreste } & \multicolumn{2}{|c|}{ Leste } & \multicolumn{2}{|c|}{ Sertão } & \multirow{2}{*}{$\begin{array}{c}\text { Média } \\
\%\end{array}$} & \\
\hline & $\mathbf{N}$ & $\%$ & $\mathbf{N}$ & $\%$ & $\mathbf{N}$ & $\%$ & & \\
\hline \multicolumn{9}{|l|}{ Critérios de confirmação } \\
\hline Laboratorial & 4140 & 11,8 & 5717 & 9,2 & 2104 & 14,7 & 10,7 & \multirow{3}{*}{$<0.0001$} \\
\hline Clínico-epidemiológico & 21208 & 60,3 & 50364 & 80,8 & 7704 & 53,8 & 70,9 & \\
\hline Ignorado/Branco & 9794 & 27,9 & 6239 & 10,0 & 4503 & 31,5 & 18,4 & \\
\hline \multicolumn{9}{|l|}{ Classificação } \\
\hline Dengue & 24686 & 70,2 & 43432 & 69,7 & 7067 & 49,4 & 67,27 & \multirow{4}{*}{$<0.0001$} \\
\hline Dengue Grave & 87 & 0,2 & 547 & 0,9 & 43 & 0,3 & 0,61 & \\
\hline Inconclusivo & 9346 & 26,6 & 17692 & 28,4 & 6266 & 43,8 & 29,80 & \\
\hline Ignorado/Branco & 1023 & 2,9 & 649 & 1,0 & 935 & 6,5 & 2,33 & \\
\hline \multicolumn{9}{|l|}{ Evolução da doença } \\
\hline Cura & 28179 & 80,19 & 51559 & 82,73 & 7866 & 54,96 & 78,38 & \multirow{3}{*}{$<0.0001$} \\
\hline Óbito por Dengue & 5 & 0,01 & 24 & 0,04 & 5 & 0,03 & 0,03 & \\
\hline $\begin{array}{l}\text { Óbito (outras causas) } \\
\text { Ignorado/Branco }\end{array}$ & $\begin{array}{c}5 \\
6953\end{array}$ & $\begin{array}{c}0,01 \\
19,79\end{array}$ & $\begin{array}{c}34 \\
10703\end{array}$ & $\begin{array}{r}0,05 \\
17,17 \\
\end{array}$ & $\begin{array}{c}5 \\
6435\end{array}$ & $\begin{array}{c}0,03 \\
44,97 \\
\end{array}$ & $\begin{array}{c}0,04 \\
21,55\end{array}$ & \\
\hline
\end{tabular}

Fonte: SINAN/SES/AL, 2016. *Teste do Qui-quadrado; $\alpha=0,05$. 


\section{DISCUSSÃO}

Apesar dos avanços tecnológicos e esforços gerados pelo Ministério da Saúde, que trabalha articulado à vigilância epidemiológica e entomológica, o cenário da dengue ainda permanece grave, repercutindo de forma negativa na saúde pública do nosso país. No que concerne ao Estado de Alagoas, a situação é semelhante, pois, no período estudado (2011-2015), foi observado um crescente aumento no número de casos, e esses encontravam-se amplamente disseminados nas três mesorregiões.

Nos anos de 2012 e 2015 foram notificados os maiores registros de casos no Estado. Em 2015, situação idêntica ocorreu no país, notificando 301,5 casos por 100.000 habitantes, evidenciando uma incidência alta na maioria dos Estados brasileiros. Tal informação pode ser justificada pela influência climática da região Nordeste, que infere intimamente na proliferação do mosquito. Nos anos que houve os maiores registros de casos no Estado de Alagoas, também foram referidos com pouca chuva e, várias regiões ao longo do ano, sofreram com a seca. O ano de 2012 foi apontado como a pior seca registrada em uma década (ALAGOAS, 2015).

Defendendo esta hipótese, um estudo enuncia que a elevada temperatura diminui as fases do ciclo de vida do mosquito, que tem uma média de 9 a 12 dias, passando para 8 dias em locais com alta temperatura, além de que aumenta a atividade hematofágica da fêmea Aedes Aegypti (CONSOLI RAGB, OLIVEIRA RL, 1994).

Assim, situações idênticas ocorrem em países latino-americanos, como Argentina, que tem revelado um aumento de casos de dengue nos meses de verão, relatando ainda, que a parte sul do país notificou poucos casos. Outro aspecto abordado tange às migrações, inferindo-se que as movimentações entre países e o turismo nacional e internacional, favorecem o elevado número de casos no país (ORELLANO PW, SALOMÓN OD, 2016).

Neste sentido, ao analisar os resultados, pode ser visto que o número de casos da dengue foi superior a 300 por 100.000 habitantes no Leste e Agreste Alagoano, número considerado de alta incidência pelo Ministério da Saúde. Fato esse que demonstra como as regiões se enquadram dentro do contexto epidêmico da dengue. Porém, o Sertão Alagoano nos anos de 2011, 2013 e 2014, apresentou uma incidência inferior a 300 casos por 100.000 habitantes.

Acredita-se que a mesorregião do Sertão Alagoano apresenta fragilidade na notificação dos casos. Pois sustenta a tese que locais secos levam a população a armazenar água, devido ao déficit no abastecimento e recolhimento de resíduos. Além disso, áreas com temperatura elevada, taxas de precipitações de chuvas e umidade do ar variável, mantêm condições favoráveis à proliferação do vetor e ao aumento no número de casos. As complexas interações entre vetor, ambiente e hospedeiro torna a dinâmica da transmissão de difícil compreensão, devido à influência dos fatores climáticos e ambientais (BANU S, et al., 2014; EHELEPOLA NDP, et al., 2015).

Quanto aos aspectos sociodemográficos, a distribuição dos casos foi maior em mulheres em todas as mesorregiões. Tais resultados podem estar associados a duas possíveis hipóteses: as características socioculturais brasileiras, pelo fato das mulheres permanecerem maiores períodos no ambiente intradomiciliar ou peridomiciliar, e devido ao homem procurar menos o serviço de saúde, quando comparado às mulheres gerando assim, uma quantidade menor de notificações do sexo masculino (BARBOSA PO, ORSOLIN P, 2013; CHITRA TV, PANICKER S, 2011; BUNYAVEJCHEVIN S, et al., 1997).

De maneira semelhante, foi identificado em um estudo realizado no México, uma maior prevalência em mulheres, embora essa diferença tenha diminuído entre os anos de 2003 e 2010 (DANTES HG, et al., 2014). Por outro lado, em uma pesquisa desenvolvida na Venezuela, houve uma maior prevalência da doença nos indivíduos do sexo masculino, mostrando que nem sempre essa tendência se repete (ORTIZ LFD, et al., 2014).

Vale ressaltar que, quando se considera as mulheres, as gestantes são mais susceptíveis a complicações da doença, principalmente por apresentarem maior incidência da forma grave (CARROLL ID, et al., 2007; 
BRASIL, 2009). Na análise do estudo, a dengue grave apresentou $0,61 \%$ em relação ao total de casos, no entanto, esse número não deve ser ignorado, cabendo aos profissionais de saúde realizar o acompanhamento sistemático da incidência de febre ou outros sintomas da dengue em mulheres no período gestacional. É válido lembrar também a possibilidade da transmissão vertical da dengue no período perinatal, que pode gerar prematuridade e até morte fetal (FIGUEIROA MN, et al., 2017).

Convém destacar, que foi evidenciado um maior número de casos em adultos, estando em conformidade com o estudo da epidemiologia da dengue no Brasil, na cidade de Santa Bárbara do Oeste, São Paulo e no Estado de Goiás (PIOVEZAN R, et al., 2012; CUNHA THCS, HAMAD GBNZ, 2018). A predominância da dengue nesse grupo é explicada, possivelmente, por estar relacionada à faixa etária que se caracteriza como fase produtiva do indivíduo, esse, por conseguinte, em contato com mais pessoas durante o dia-a-dia, encontra-se mais suscetível a ser picado pelo mosquito vetor, o Aedes aegypti, que pode ter se alimentado previamente de indivíduos contaminados em ambiente domiciliar, peridomiciliar e laborais (CUNHA THCS, HAMAD GBNZ, 2018).

Quanto à escolaridade, deve-se levar em consideração que se trata de uma variável pouco registrada nas fichas de notificação compulsória dos casos de Dengue em Alagoas, com mais de $50 \%$ dos casos registrados como ignorados ou deixados em branco no momento da notificação. Apesar da fragilidade desses dados, o nível de escolaridade dos pacientes mais acometidos pela doença, em todas as mesorregiões, foi o de ensino fundamental. Corroborando com estes dados, estudos mostram que quanto mais baixo o nível de escolaridade dos indivíduos, menor o seu conhecimento quanto aos aspectos relacionados à dengue o que, por sua vez, aumenta o risco de infecção de grupos vulneráveis (VIDAL ECF, et al., 2015).

Ao avaliar o local de residência, foi constatado o maior número de casos da doença na zona urbana, com $66,2 \%$ dos casos. Estudo similar apresenta que a ocorrência da dengue pode variar entre as localidades, onde o aspecto urbano-social pode criar ambientes que favoreçam ou não a proliferação do vetor, que deposita seus ovos em recipientes artificiais, localizados no peridomicílio (ARAÚJO TP, et al., 2002; FIGUEIRÓ AC, et al., 2011).

Em um estudo realizado no município de Picos, no Estado do Piauí, que teve como objetivo realizar um levantamento de dados sobre a situação da dengue como problema de saúde pública, destacando-se a distribuição do mosquito vetor e a ocorrência da doença, mostrou que tal município está em constante estado de alerta e que qualquer descontinuidade nos programas de combate ao vetor pode alterar o quadro para a situação de risco e, consequentemente, ocorrência de surto de dengue (COSTA AR, et al., 2016).

Desta forma, realizar visitas nos domicílios são de suma importância para a construção de um indicador de risco urbano de transmissão de doenças, visto que tais intervenções proporcionam ações para o conhecimento, detecção e prevenção no que tange às mudanças nos fatores determinantes e condicionantes de saúde coletiva, afim de contribuir a evitar a ocorrência da dengue em áreas livres de circulação, além de detectar e controlar precocemente as epidemias (BRAGA C, et al., 2001).

As mudanças demográficas ocorridas nos países subdesenvolvidos a partir da década de 60, consistiram num intenso fluxo migratório rural-urbano, resultando num "inchaço" das cidades, que não conseguiram dotarse oportunamente de equipamentos e facilidades que atendessem às necessidades dos migrantes, entre as quais se incluem as de habitação e saneamento básico. Boa parte da população passou a viver em favelas, invasões e cortiços (TAUIL PL, 2001) assim sendo, além do maior contingente populacional estar concentrado nas áreas urbanas, essas podem estar mais vulneráveis a áreas com ambientes propícios à proliferação do Aedes aegypti.

A Mesorregião do Leste Alagoano chama a atenção pelo índice acima da média total no que tange ao exame sorológico. Os casos em que não foram realizados exames de sorologia $(80,8 \%)$ alteram significativamente a confiabilidade dos resultados, uma vez que muitos casos podem ter sido triados de maneira errônea, inclusive levando à diagnóstico falso-negativo da doença. Quanto aos ignorados e brancos, o alto índice nas demais regiões também é preocupante, podendo levar a um prejuízo ainda maior das informações contidas no SINAN. 
Com relação aos resultados laboratoriais, de acordo com as Diretrizes Nacionais para a Prevenção e Controle de Epidemias de Dengue, vigente no período epidêmico, é obrigatório realizar a sorologia de 10\% dos casos suspeitos de dengue clássica e em todos os casos graves (BRASIL, 2009).

Apesar da suspeita da doença ser uma questão clínica, a confirmação sorológica deve ser realizada por exame de sangue, para detectar, de fato, anticorpos contra o vírus, no entanto, a literatura recomenda a realização da sorologia depois do sexto dia após o começo dos sintomas, pois sorologias colhidas antes deste prazo podem originar resultados falsos-negativos (ASSUNÇÃO ML, AGUIAR AM, 2014). Este fato pode explicar o elevado índice de critério de confirmação clínico-epidemiológico em comparação ao critério de confirmação laboratorial, com cerca de 70,93\% e 10,70\%, respectivamente, dos casos registrados pelo SINAN em Alagoas.

O critério de caso adotado para a dengue inclui aspectos clínicos e laboratoriais, conforme preconizado pelo Ministério da Saúde: critério laboratorial ou critério clínico-epidemiológico. Uma das formas de confirmação laboratorial dos casos suspeitos é a sorologia (detecção de lgM antidengue) (BRASIL, 2018).

Sabe-se que a suspeita da doença é uma questão clínica-epidemiológica, entretanto a confirmação será através de exames sorológicos (sorologia IgM, NS1 teste rápido ou ELISA, isolamento viral, PCR, Imunohistoquímica). A identificação da etiologia de dengue apenas é possível através da cultura do vírus em laboratório de referência e, embora a comprovação do diagnóstico de dengue não seja útil para o tratamento da doença, o exame sorológico do diagnóstico poderá contribuir para outros fins, como Vigilância Epidemiológica e estatística (NARVAEZ F, et al., 2011).

No presente estudo, observou-se, assim como na análise de outros autores, a predominância da classificação dengue $(67,2 \%)$. Porém, deve-se considerar que a região do Leste Alagoano registrou $0,9 \%$ dos casos grave da doença, acima da média total $(0,61 \%)$. Por ser a região mais populosa do Estado e onde está inserida a capital do mesmo, Maceió, a probabilidade de casos graves da doença aumenta. Isso explica também o fato dessa mesorregião registrar a maior porcentagem de cura do Estado. A mesorregião do Sertão Alagoano apresentou um percentual de casos inconclusivos da dengue, superior à média total $(29,8 \%)$, podendo ser subestimados os casos de dengue grave.

Cabe destacar o aumento de 5,5\% de casos da doença em crianças na mesorregião do Sertão Alagoano. A dengue nessa faixa etária apresenta manifestações clínicas similares a outras afecções infantis, tornando o diagnóstico mais difícil (JAIN A, CHATUVERDI UC, 2010). Na presença de comorbidades como asma, diabetes e anemia falciforme, o risco do agravamento da dengue se torna maior (GUZMÁN MG, et al., 2009).

Estudos indicam que os serviços de saúde possuem as condições necessárias para o atendimento adequado aos pacientes com dengue. No entanto, o que se observou, são problemas relacionados ao manejo clínico dos casos, evidenciados por insuficiência, inaptidão e negligência envolvidos durante a ocorrência das mortes (FIGUEIRÓ AC, et al., 2011). No que tange à evolução da doença para óbito, observou-se a ocorrência de 34 casos $(0,03 \%)$ registrados no Estado, estes valores podem inicialmente serem considerados baixos, porém, ao se analisar que $24.091(21,55 \%)$ casos foram ignorados, fica perceptível que há uma propensão a mascarar um número maior de óbitos ou de complicações decorrentes da dengue. Considerando que se trata de uma morbidade de fácil diagnóstico e tratamento, o número de óbitos notificados ainda é uma preocupação para a saúde pública. As mortes por dengue são consideradas evitáveis, o que ressalta a necessidade de promover uma assistência adequada e melhorias no fluxo de informações de saúde, a fim de gerar ações efetivas no combate à doença (FIGUEIRÓ AC, et al., 2011).

Considerando que este trabalho foi desenvolvido a partir de dados secundários, foram vivenciadas algumas limitações que afetaram a análise dos dados em decorrência de lacunas identificadas no preenchimento das notificações compulsórias com persistência de dados ignorados e espaços em branco. Pese a identificação de falhas de notificação nos serviços de saúde, o conjunto de dados sustenta informações relevantes no que se refere a situação epidemiológica da dengue no Estado de Alagoas. Recomenda-se que novos estudos sejam realizados na temática, a fim de contribuir com o processo de monitoramento dessa doença que ainda mantém um crescimento acima das recomendações do Ministério da 
Saúde e da Organização Mundial da Saúde. Espera-se que as informações demonstradas neste estudo possam colaborar com os gestores, equipes técnicas locais e profissionais da saúde, sensibilizando-os em relação à importância da dengue para o Estado de Alagoas, a partir da severidade do seu quadro epidemiológico evidenciada no presente estudo.

\section{CONSIDERAÇÕES FINAIS}

A dengue continua como importante agravo, devido a sua alta incidência, com apresentação de períodos epidêmicos, evoluções para o óbito, e, assim, com grandes repercussões na saúde pública do Estado de Alagoas e do país. Este estudo permitiu apontar os principais elementos que definem o perfil epidemiológico da doença no Estado de Alagoas, com o predomínio de adultos do sexo feminino de raça parda que residem em áreas urbanas. A Mesorregião Leste foi apontada com os índices mais elevados de casos, nesta encontrase a capital Maceió. Quanto à confirmação dos casos, a maioria foi por critério clínico-epidemiológico. Estes dados são importantes no tocante a elaboração de ações de controle, tratamento e vigilância da doença. É preciso efetuar campanhas de esclarecimento e prevenção da dengue à população, no intuito de criar uma cultura preventiva a partir da mudança de atitude das pessoas, no que concerne a proliferação do mosquito vetor.

\section{AGRADECIMENTOS}

A Fundação de Amparo à Pesquisa do Estado de Alagoas e ao Conselho Nacional de Desenvolvimento Científico e Tecnológico pela concessão das bolsas de iniciação cientifica.

\section{REFERÊNCIAS}

1. AlAGOAS (Estado). Secretaria de Estado do Meio Ambiente e dos Recursos Hídricos. Diretoria de Meteorologia. Relatório Anual das Condições Meteorológicas e Evolução da Seca no Estado de Alagoas. 2015. Disponível em: http://dados.al.gov.br/dataset/c2e1c14e-5fd7-442c-92f4467cf98ba420/resource/a3121284-8a9d-4208-be94a0ff17af5d45/download/relatorioanual2015.pdf. Acesso em: 27 nov. 2017.

2. ARAÚJO TP, et al. Diagnostico Sorológico de infecção por dengue e febre amarela em suspeitos no Estado do Para, Brasil, 1999. Revista da Sociedade Brasileira de Medicina Tropical, 2002; 35(6):579-584.

3. ARAÚJO VEM, et al. Aumento da carga de dengue no Brasil e unidades federadas, 2000 e 2015: análise do Global Burden of Disease Study 2017. Revista Brasileira de Epidemiologia [Internet], 2017; 20(1):205-216.

4. ASSUNÇÃO ML, AGUIAR AM. Perfil clínico-epidemiológico da dengue no município de Juscimeira. Revista de Epidemiologia e Controle de Infecção, 2014; 4(4):249-253.

5. BANU S, et al. Projecting the impact of climate change on Dengue transmission in Dhaka, Bangladesh. Environment International, 2014; 63:137-142.

6. BARBOSA PO, ORSOLIN P. Estudo epidemiológico da dengue nos principais municípios do Alto Paranaíba-MG. Revista Perquirerê, 2013; 10(2):29-45.

7. BARRETO ML, et al. Sucessos e fracassos no controle de doenças infecciosas no Brasil: o contexto social e ambiental, políticas, intervenções e necessidades de pesquisa. The Lancet, 2011; 3:47-60.

8. BARROS AHC, et al. Climatologia do Estado de Alagoas - Dados eletrônicos. Embrapa Solos, Recife, 2012. Disponível em: https://www.embrapa.br/solos/busca-de-publicacoes/ /publicacao/950797/climatologia-doestado- de-alagoas. Acesso em: 15 fev. 2017.

9. BRAGA C, et al. Avaliação de indicador socioambiental utilizado no rastreamento de áreas de transmissão de filariose linfática em espaços urbanos. Cadernos de Saúde Pública, 2001; 17(5):1211-1218.

10. BRASIL. Ministério da Saúde. Dengue: causas, sintomas, tratamento e prevenção. 2018. Disponível em: http://portalms.saude.gov.br/saude-de-a-z/dengue. Acesso em: 27 nov. 2018.

11. BRASIL. Ministério da Saúde. Secretaria de Vigilância em Saúde. Boletim Epidemiológico. Monitoramento dos casos de dengue, febre de chikungunya e febre pelo vírus Zika até a Semana Epidemiológica 15, 2017. Disponível em: http://portalarquivos.saude.gov.br/images/pdf/2017/maio/05/Monitoramento-dos-casos-de-dengue-febre-dechikungunya-e-febre-pelo-virus-Zika-ate-a-Semana-Epidemiologica.pdf. Acesso em: 27 nov. 2017.

12. BRASIL. Ministério da Saúde. Secretaria de Vigilância em Saúde. Departamento de Vigilância Epidemiológica. Diretrizes nacionais para prevenção e controle de epidemias de dengue, Brasília, 2009. Disponível em: 
http://bvsms.saude.gov.br/bvs/publicacoes/diretrizes_nacionais_prevencao_controle_dengue.pdf. Acesso em: 27 nov. 2017.

13. BRASIL. Ministério da Saúde. Secretaria Executiva. Subsecretaria de Planejamento e Orçamento. Plano Nacional de Saúde PNS: 2012-2015, Brasília, $2012 . \quad$ Disponível em:http://conselho.saude.gov.br/biblioteca/Relatorios/plano_nacional_saude_2012_2015.pdf. Acesso em: 27 nov. 2017.

14. BUNYAVEJCHEVIN S, et al. Dengue hemorrhagic fever during pregnancy: antepartum, intrapartum and postpartum management. Journal of Obstetrics and Gynaecology Research, 1997; 23:445-448.

15. CABEZAS $C$, et al. Dengue en el Peru: a un cuarto de siglo de su reemergencia. Revista Peruana de Medicina Experimental y Salud Publica, 2015; 32(1):146-156.

16. CARROLL ID, et al. Dengue fever and pregnancy - a review and comment. Travel Medicine and Infectious Diseases, 2007; 5:182-188.

17. CHITRA TV, PANICKER S. Maternal and fetal outcome of dengue fever in pregnancy. Journal of Vector Borne Diseases, $2011 ; 48: 210-213$.

18. CONSOLI RAGB, OLIVEIRA RL. Principais mosquitos de importância sanitária no Brasil. Rio de Janeiro: Fiocruz, 1994.

19. COSTA AR, et al. Análise do controle vetorial da dengue no sertão piauiense entre 2007 e 2011 . Cadernos de Saúde Coletiva, 2016; 24(3):275-281.

20. CUNHA THCS, HAMAD GBNZ. Condições Ambientais como Fator de Risco. Prevalência da Dengue. 2018. Disponível em: http://www.editorarealize.com.br/revistas/ enect/trabalhos/Comunicacao_249_2.pdf>. Acesso em: 04 dez. 2018.

21. DANTES HG, et al. Epidemiological trends of dengue disease in Mexico (2000-2001): a systematic literature search and analysis. PLOS Neglected Tropical Diseases, 2014; 8(11):3158.

22. DIAS LBA, et al. Dengue: transmissão, aspectos clínicos, diagnóstico e tratamento. Medicina (Ribeirão Preto), 2010; 43(2):143-152.

23. DONALISIO MR, et al. Arboviroses emergentes no Brasil: desafios para a clínica e implicações para a saúde pública. Revista de Saúde Pública, 2017; 51(30):1-6.

24. EHELEPOLA NDP, et al. A study of the correlation between Dengue and weather in Kandy City, Sri Lanka (2003-2012) and Lessons Learned. Infectious Diseases of Poverty, 2015; 4(42):1-14.

25. FIGUEIRÓ AC, et al. Óbito por dengue como evento sentinela para avaliação da qualidade da assistência: estudo de caso em dois municípios da Região Nordeste, Brasil, 2008. Cadernos de Saúde Pública, 2011; 27(12): 2373-2385.

26. FIGUEIROA MN, et al. Prevalence of Arbovirus Infections Among Pregnant Women at a Maternity Hospital School. International Archives of Medicine, 2017; 10(142):1-10.

27. GUZMÁN MG, et al. Dengue: where are we today? Malaysan Journal of Medical Sciences, 2009; 16(3):5-12.

28. JAIN A, CHATUVERDI UC. Dengue in infants: an overiew. FEMS Immunology and Medical Microbiology, 2010; 59(2):119-130.

29. NARVAEZ F, et al. Evaluation of the traditional and revised WHO classifications of Dengue disease severity. PLoS Neglected Tropical Diseases, 2011; 5(11):1397.

30. ORELLANO PW, SALOMÓN OD. Las Vacunas Contra el Dengue ¿Una realidad para la Argentina? Medicina (Buenos Aires), 2016; 76(2):1-5.

31. ORTIZ LFD, et al. Comportamiento clinico-epidemiologico del dengue en un CDI de Venezuela. Revista de Información Cientifica, 2014; 88(6):982-990.

32. PIOVEZAN R, et al. Estudo epidemiológico dos casos de dengue no município de Santa Bárbara d'Oeste/SP - 2010. BEPA, Boletim Epidemiológico Paulista (Online), 2012; 9(104):4-13.

33. ROMERO-VEGAI L, et al. Evaluacion de la notificacion del dengue. Revista de Saúde Publica, 2014; 48(6):899-905.

34. SILVA MMO, et al. Accuracy of Dengue Reporting by National Surveillance System, Brazil. Emerging Infectious Diseases, 2016; 22(2):336-339.

35. SINAN. Ministério da Saúde. Portal da Saúde. Situação Epidemiológica/Dados. 2016. Disponível em: http://portalsaude.saude.gov.br/index.php/situacao-epidemiologica-dadosdengue. Acesso em: 20 abr. 2016.

36. SINAN. Ministério da Saúde. Portal da Saúde. Dengue. 2018. Disponível em: http://portalsinan.saude.gov.br/dengue. Acesso em: 27 nov. 2018.

37. SOUZA RP, et al. Dengue virus type 4 phylogenetics in Brazil. 2011: looking beyond the veil. Plos Neglected Tropical Diseases, 2011; 5(12):1-7.

38. TAUIL, P. L. Urbanização e ecologia do dengue. Cadernos de Saúde Pública, 2001; 17:99-102.

39. VIDAL ECF, et al. Characterization of Temporal Trends of Dengue Fever in Municipalities in the Brazilian Northeast Outback. International Archives of Medicine, 2015; 8(113): 1-10.

40. WORLD OF HEALTH ORGANIZATION (WHO). Dengue: guidelines for diagnosis, treatment, prevention and control. New edition: Geneva, 2009. 